\title{
17-Hydroxyprogesterone caproate to prolong pregnancy after preterm rupture of the membranes: early termination of a double-blind, randomized clinical trial
}

C Andrew Combs ${ }^{1,8^{*}}$, Thomas J Garite ${ }^{2}$, Kimberly Maurel ${ }^{3}$, Kimberly Mallory ${ }^{1}$, Rodney K Edwards ${ }^{4}$, George Lu ${ }^{5}$, Richard Porreco ${ }^{6}$ and Anita Das ${ }^{7}$, for the Obstetrix Collaborative Research Network

\begin{abstract}
Background: Progestational agents may reduce the risk of preterm birth in women with various risk factors. We sought to test the hypothesis that a weekly dose of 17-hydroxyprogesterone caproate (17P) given to women with preterm rupture of the membranes (PROM) will prolong pregnancy and thereby reduce neonatal morbidity.

Methods: Double-blind, placebo-controlled randomized clinical trial. Women with PROM at 23.0 to 31.9 weeks of gestation were randomly assigned to receive a weekly intramuscular injection of $17 \mathrm{P}$ ( $250 \mathrm{mg}$ in $1 \mathrm{~mL}$ castor oil) or placebo ( $1 \mathrm{~mL}$ castor oil). The primary outcome was the rate of continuing the pregnancy until 34.0 weeks of gestation or until documentation of fetal lung maturity at 32.0 to 33.9 weeks of gestation. Planned secondary outcomes were duration of latency period and rate of composite neonatal morbidity. Enrollment of 111 participants per group, 222 total, was planned to yield $80 \%$ power to detect an increase in the primary outcome from $30 \%$ with placebo to $50 \%$ with $17 \mathrm{P}$.
\end{abstract}

Results: Twelve women were enrolled of whom 4 were randomly assigned to receive 17P and 8 to receive placebo. The trial was terminated prematurely because of two separate issues related to the supply of $17 \mathrm{P}$. No adverse events attributable to $17 \mathrm{P}$ were identified.

Conclusion: Because of premature termination, the trial does not have adequate statistical power to evaluate efficacy or safety of 17P in women with PROM. Nonetheless, ethical principles dictate that we report the results, which may contribute to possible future metaanalyses and systematic reviews.

Trial Registration: ClinicalTrials.gov: NCT01119963

Supported by a research grant from the Center for Research, Education, and Quality, Pediatrix Medical Group, Sunrise, FL

\section{Background}

Preterm rupture of the membranes (PROM) occurs in $2-4 \%$ of singleton pregnancies, yet accounts for $18-20 \%$ of perinatal mortality in the United States [1]. PROM is frequently followed by preterm birth (PTB) within a few days [1,2]. Management of PROM involves a weighing of risks of prematurity complications versus risks of

\footnotetext{
* Correspondence: andrewcombs@me.com

'Obstetrix Medical Group, Center for Research, Quality, and Education, San Jose, CA, USA

Full list of author information is available at the end of the article
}

prolonging the pregnancy, such as chorioamnionitis, placental abruption, or cord prolapse. With PROM before 32 weeks of gestation, the morbidity of PTB is high, so attempts to prolong the pregnancy are generally advocated $[1,2]$, a strategy called "expectant management." With PROM after 34 weeks, or after 32 weeks if fetal lung maturity is documented, the complications of PTB are less and the risks of infection and other complications of expectant management remain, so delivery is generally recommended $[1,2]$.
C Biomed Central

C 2011 Combs et al.; licensee BioMed Central Ltd. This is an Open Access article distributed under the terms of the Creative Commons Attribution License (http://creativecommons.org/licenses/by/2.0), which permits unrestricted use, distribution, and reproduction in any medium, provided the original work is properly cited. 
Attempts to prolong the pregnancy with expectant management of PROM are often unsuccessful. The rate of delivery during expectant management of PROM roughly follows a "half-life" function, with about half of patients delivering within a week and about half of the remainder delivering with each subsequent week [3-6]. Antibiotic prophylaxis after PROM has been shown to prolong the latency period [3-7] (interval from PROMto-delivery) and reduce neonatal morbidity [6,7]. Tocolysis has not been shown to be effective after PROM $[8,9]$.

Progestational agents such as progesterone and 17hydroxyprogesterone caproate (17P) have been shown to reduce the rate of $\mathrm{PTB}$ in women with certain risk factors for $\mathrm{PTB}$, including women with a history of a prior PTB [10-12], women with a short cervix [13-15], or women who have had an acute episode of preterm labor successfully suppressed after tocolysis $[16,17]$. It is unknown whether 17P or other progestins might be beneficial after PROM. Progestins have multiple actions that might potentially help to prolong pregnancy after PROM, including suppression of inflammatory mediators and decreased production of contraction-associated proteins such as gap junction proteins and oxytocin receptors [18]. Briery and colleagues reported a small trial that showed no benefit of $17 \mathrm{P}$ versus placebo after PROM [19], but only 35 subjects had actually received $17 \mathrm{P}$, so statistical power to reach a negative conclusion was rather limited.

The present study was undertaken to test the hypothesis that $17 \mathrm{P}$ given to mothers with PROM before 32 weeks of gestation will prolong the pregnancy and thereby reduce neonatal morbidity.

\section{Methods}

The trial was sponsored, designed, and conducted by the Obstetrix Collaborative Research Network, a consortium of maternal-fetal medicine practices across the United States. The trial was approved by the independent Institutional Review Board (IRB) at each site. The study was conducted under Investigational New Drug (IND) Number 107785 through the United States Food and Drug Administration (FDA). The trial was registered on http://clinicaltrials.gov, \#NCT01119963. An independent Data and Safety Monitoring Board (DSMB) supervised the trial, reviewed adverse event reports, and approved the premature termination of the trial. Additional File 1 contains the complete, IRB-approved, final protocol.

Women were eligible if they were at least 18 years old, had a singleton pregnancy at 23.0 to 31.9 weeks of gestation, and PROM. PROM was defined as either (a) documentation of vaginal leakage of indigo carmine dye instilled via amniocentesis; (b) a positive Amnisure ${ }^{\circledR}$ test (Amnisure International, Cambridge, MA); or (c) two or more of the following: nitrazine test of vaginal secretions with $\mathrm{pH} 7$ or higher, ferning of vaginal secretions, gross pooling of clear fluid in the posterior vaginal fornix, or ultrasound exam showing oligohydramnios. We excluded women with active preterm labor, defined as 8 or more uterine contractions per hour that were perceived by the patient and/or a cervical dilation $4 \mathrm{~cm}$ or more. The definition of PROM did not require that the rupture of membranes had occurred before the onset of labor (commonly called "premature" or "prelabor" PROM); that is, women were eligible if they had labored before PROM provided that they were not in active labor, as defined, at the time of enrollment. We excluded women with contraindications to expectant management (such as suspected intraamniotic infection, nonreassuring fetal heart rate tracing, fetal death, preeclampsia, active uterine bleeding, or documented fetal lung maturity), with known fetal abnormalities (such as major congenital malformation, viral infection, or hydrops), with history of allergy to $17 \mathrm{P}$ or castor oil, with medical conditions that might adversely interact with 17P (such as asthma requiring medications, renal insufficiency, seizure disorder, ischemic heart disease, cholecystitis, impaired liver function, or history of venous thromboembolism, breast cancer or depression requiring hospitalization), with medical conditions treated with systemic steroid medications, or with a cervical cerclage present at the time of PROM. Eligible women were approached by a physician or research nurse and were offered participation in the trial.

Women who gave informed consent were randomly assigned in a 1:1 ratio to receive either $17 \mathrm{P}(250 \mathrm{mg}$ in castor oil, $1 \mathrm{~mL}$ total volume, intramuscular injection weekly) or an identical-appearing placebo $(1 \mathrm{~mL}$ castor oil only). A computer-generated random-number sequence was used by the trial statistician to generate a randomization code book kept at each site's inpatient pharmacy. Study medications (17P versus placebo) were prepared by McGuff Pharmaceuticals (Newport, California) according to the IND specifications, which followed current Good Manufacturing Practices (cGMP). Medications were provided in $5 \mathrm{~mL}$ multi-dose vials, specially labeled for the study and number-coded to correspond with the randomization code book. Randomization was stratified by gestational age, 23.0-25.9 weeks, 26.0 to 28.9 weeks, and 29.0 to 31.9 weeks. Participants and research personnel were blinded to group assignment throughout, from before enrollment until after completion of all case report forms and resolution of all data queries. The code was not broken until after the database was "locked."

Each week from randomization until delivery, the assigned medication (17P or placebo) was drawn into a syringe labeled "Study medication: progesterone or 
placebo" by the inpatient pharmacy at each site, delivered to the nursing unit, and administered by a registered nurse. In the syringes, $17 \mathrm{P}$ and placebo appeared visually identical.

Other than the administration of study medication (17P or placebo), the remainder of each patient's clinical care followed standard clinical management for PROM. The investigators agreed in advance on many items of standard management. These included inpatient hospitalization of all patients until delivery, administration of a single course of antenatal corticosteroids, broad-spectrum antibiotic prophylaxis for 1 week, avoidance of tocolytics (except during the $48 \mathrm{~h}$ after the first dose of corticosteroids), and fetal heart rate monitoring at least $1 \mathrm{~h}$ daily. We encouraged amniocentesis to rule-out intraamniotic infection before enrollment, but did not require this. We discouraged digital examination of the cervix, but did not exclude subjects who had already had digital examinations. The protocol called for collection of amniotic fluid from vaginal leakage at 32.0 weeks or beyond for assessment of fetal lung maturity according to whatever test was in use at the local site. Intrapartum antibiotic prophylaxis (e.g. group B streptococcus coverage) was encouraged but not mandated. A protocol was in place for evaluation and management of suspected membrane resealing, but this was not used because all the participants continued leaking amniotic fluid until delivery. Management decisions not specifically addressed by protocol were left to the discretion of the managing physician, including route of delivery, choice of antibiotics, and other matters.

The primary outcome was defined as prolongation of the pregnancy until a favorable gestational age, which we defined as either 34.0 weeks of gestation or documentation of fetal lung maturity at 32.0 to 33.9 weeks. The investigators agreed that continuation of pregnancy beyond these time points was not indicated. Secondary outcomes were latency (interval from randomization to delivery) and composite neonatal morbidity, which was defined per Mercer et al. [6] as one or more of: stillbirth, neonatal death, infant death before hospital discharge, respiratory distress syndrome (RDS), intracranial hemorrhage $(\mathrm{ICH})$ grade 3 or 4 , necrotizing enterocolitis (NEC) stage 2 or 3, culture-proven neonatal sepsis within $72 \mathrm{~h}$ of birth. In addition to the components defined by Mercer et al. [6], our definition of composite neonatal morbidity included periventricular leukomalacia (characteristic lesions in the subcortical white matter seen on cerebral imaging studies within $96 \mathrm{~h}$ of birth.)

Sample size calculations indicated that we would need 105 participants in each group (17P or placebo) to yield $80 \%$ power to detect a $20 \%$ absolute increase in the rate of the primary outcome from $30 \%$ in the placebo group to $50 \%$ in the $17 \mathrm{P}$ group. This was adjusted to 111 per group to account for a possible $5 \%$ rate of loss-to-follow-up due to membrane resealing or other factors. A single interim analysis was planned when data were available for $50 \%$ of the total sample, but this was not performed owing to early termination of the study. Because of early termination, the trial is grossly underpowered; therefore, we present only descriptive statistics by treatment group and we did not perform any formal statistical tests of potential between-group differences.

The trial was designed, conducted, analyzed, and reported according to the principles outlined in the CONSORT Statement and Checklist [20].

\section{Results}

From October, 2010 through January, 2011, twelve participants were enrolled, of whom 4 were randomly assigned to receive 17P and 8 were assigned to receive placebo. Figure 1 is a flow diagram showing the number of women at each stage of the trial.

On December 28, 2010, the FDA sent a Warning Letter [21] to McGuff Pharmaceuticals citing certain violations of cGMP in the company's manufacturing facility. Officials at McGuff disclosed this letter to us, stating that it did not relate to the production of $17 \mathrm{P}$ or placebo for our trial because the study medications were prepared in a segregated facility, not the general manufacturing line of the company cited in the Warning Letter. McGuff had sent periodic aliquots to an independent testing laboratory to verify the potency, sterility, and stability of the preparations throughout this trial and our previous trials evaluating 17P in twin [22] and triplet [23] pregnancies. Despite these reassurances, our DSMB recommended that we seek specific guidance from the FDA as to whether the Warning Letter impacted our trial. The FDA Division of Reproductive and Urologic Drug Products asked for copies of the documentation of the independent testing. Despite extensive documentation that the samples were sterile, pure, and stable, the FDA placed the trial on "Full Clinical Hold" on January 24, 2011. At that time, two women were still receiving study medications and we immediately discontinued any further administration of the drugs to them. We stopped all further recruitment into the study and notified all the local-site IRBs and the DSMB. We returned all the study medications to McGuff to be quarantined. We had planned to petition the FDA to remove the clinical hold and then to resume enrollment after McGuff had satisfactorily addressed the concerns outlined in the Warning Letter.

On February 4, 2011, the FDA granted approval to KV Pharmaceuticals to produce and distribute a formulation of 17-hydroxyprogesterone caproate under 


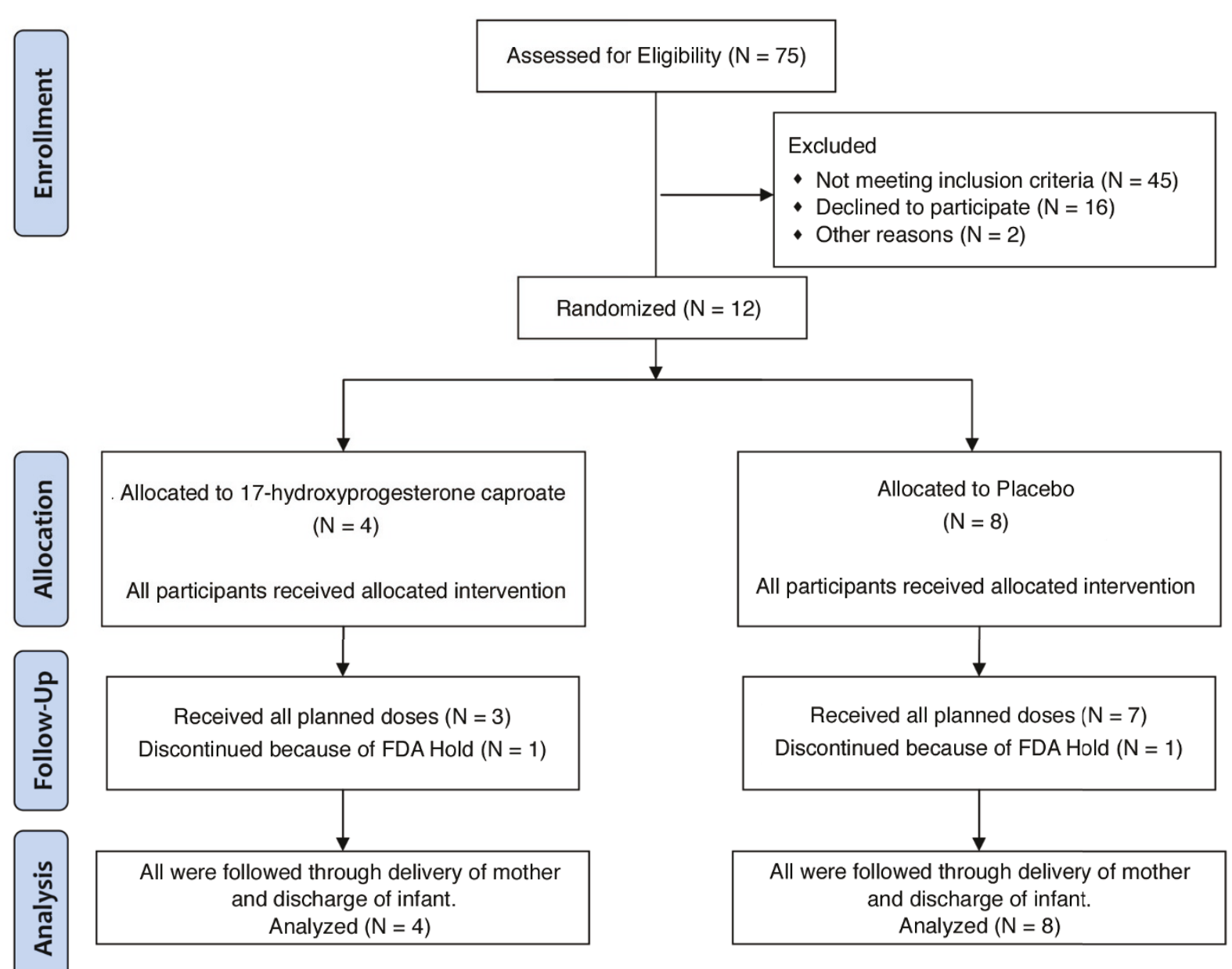

Figure 1 Flow diagram showing number of participants at each stage of trial.

the trade name Makena ${ }^{\mathrm{TM}}$. With the availability of an FDA-approved formulation, an official at McGuff notified us that they would no longer be able to prepare medications for our trial. We considered the option of resuming the trial using Makena, but this would have resulted in a "blended" trial with medications obtained from 2 different sources. Although we had independent testing suggesting that the McGuff preparation was pure and stable, we felt that a blended trial would always be plagued by questions about the validity of combining subjects whose medications were obtained from two distinctly different sources. Thus we elected to terminate the present study and report the results. This decision was reviewed and approved by the DSMB.

Table 1 summarizes the baseline characteristics of those in each group. Table 2 summarizes the primary outcome and secondary outcomes related to pregnancy prolongation. Table 3 summarizes neonatal outcomes.
Table 4 shows other outcomes of interest. Table 5 lists the participating sites. Additional File 2 presents the deidentified individual participant raw data.

There was one neonatal death in each group. In the 17P group, the mother experienced PROM at 23.7 weeks of gestation, was randomized at 24.0 weeks, was diagnosed with chorioamnionitis 2 days later, and underwent induction of labor. She delivered at $610 \mathrm{~g}$ male infant who ultimately developed necrotizing enterocolitis and died at 24 days of life. In the placebo group, the mother had PROM at 19.9 weeks, was randomized at 24.0 weeks and started spontaneous labor 8 days later. The $1000 \mathrm{~g}$ male infant had severe respiratory distress and died shortly after birth.

\section{Discussion}

Because the trial was prematurely terminated, it is obviously underpowered to make conclusions as to the efficacy or safety of $17 \mathrm{P}$ in women with PROM. 
Table 1 Baseline characteristics of study subjects

\begin{tabular}{|c|c|c|}
\hline & $\begin{array}{c}\text { 17-Hydroxyprogesterone } \\
\text { Caproate }\end{array}$ & Placebo \\
\hline & $(\mathrm{N}=4)$ & $(\mathrm{N}=8)$ \\
\hline Maternal Age (years) & $28 \pm 3$ & $33 \pm 6$ \\
\hline $\begin{array}{l}\text { Gestational Age at PROM } \\
\text { (weeks) }\end{array}$ & $25 \pm 7$ & $26 \pm 4$ \\
\hline $\begin{array}{l}\text { Gestational Age at } \\
\text { Randomization (weeks) }\end{array}$ & $28 \pm 3$ & $27 \pm 3$ \\
\hline $23.0-25.9$ wks & $1(25 \%)$ & $4(50 \%)$ \\
\hline $26.0-28.9$ wks & $1(25 \%)$ & $\begin{array}{c}1 \\
(12.5 \%)\end{array}$ \\
\hline $29.0-31.9$ wks & $2(50 \%)$ & $\begin{array}{c}3 \\
(37.5 \%)\end{array}$ \\
\hline $\begin{array}{l}\text { Interval from PROM to } \\
\text { Randomization (days) }\end{array}$ & $3(1-79)$ & $\begin{array}{l}1.5(0- \\
29)\end{array}$ \\
\hline Prepregnancy Weight (pounds) & $157 \pm 35$ & $\begin{array}{c}162 \pm \\
37\end{array}$ \\
\hline Body Mass Index (kg/M²) & $24 \pm 7$ & $27 \pm 6$ \\
\hline Body Mass Index $>30 \mathrm{~kg} / \mathrm{M}^{2}$ & $1(25 \%)$ & $\begin{array}{c}3 \\
(37.5 \%)\end{array}$ \\
\hline Nulliparous & $3(75 \%)$ & $\begin{array}{c}5 \\
(62.5 \%) \\
\end{array}$ \\
\hline History of Prior Preterm Birth & 0 & 0 \\
\hline $\begin{array}{l}\text { Progestins Used Prior to } 15 \\
\text { Weeks }\end{array}$ & $1(25 \%)$ & $2(25 \%)$ \\
\hline \multicolumn{3}{|l|}{ Conception } \\
\hline Spontaneous & $3(75 \%)$ & $\begin{array}{c}7 \\
(87.5 \%) \\
\end{array}$ \\
\hline In Vitro Fertilization & $1(25 \%)$ & 0 \\
\hline Intrauterine Insemination & 0 & $\begin{array}{c}1 \\
(12.5 \%)\end{array}$ \\
\hline Married/Living with Partner & $3(75 \%)$ & $\begin{array}{c}7 \\
(87.5 \%) \\
\end{array}$ \\
\hline College Education or More & $1(25 \%)$ & $\begin{array}{c}5 \\
(62.5 \%) \\
\end{array}$ \\
\hline \multicolumn{3}{|l|}{ Ethnicity } \\
\hline Caucasian & $3(75 \%)$ & $6(75 \%)$ \\
\hline African-American & $1(25 \%)$ & $\begin{array}{c}1 \\
(12.5 \%) \\
\end{array}$ \\
\hline Native American & 0 & $\begin{array}{c}1 \\
(12.5 \%) \\
\end{array}$ \\
\hline \multicolumn{3}{|c|}{ Reported Antepartum Substance Use } \\
\hline Alcohol, Rare & 0 & $\begin{array}{c}1 \\
(12.5 \%) \\
\end{array}$ \\
\hline Marijuana & $1(25 \%)$ & $\begin{array}{c}1 \\
(12.5 \%) \\
\end{array}$ \\
\hline Tobacco & 0 & $2(25 \%)$ \\
\hline Other & 0 & 0 \\
\hline
\end{tabular}

Results expressed as Mean \pm SD, Median (range), or N (\%).

Premature termination of a clinical trial raises serious ethical dilemmas. As noted in an editorial in The Lancet [24], "There is ... a moral responsibility to ensure that the commitments shown by physicians to
Table 2 Primary outcome and gestational age outcomes

\begin{tabular}{|c|c|c|}
\hline & $\begin{array}{c}17- \\
\text { Hydroxyprogesterone } \\
\text { Caproate }\end{array}$ & Placebo \\
\hline & $(\mathrm{N}=4)$ & $(\mathrm{N}=8)$ \\
\hline \multicolumn{3}{|l|}{ Primary Outcome } \\
\hline $\begin{array}{l}\text { Delivery at } 34.0 \text { weeks or } \\
\text { more }\end{array}$ & 0 & 0 \\
\hline $\begin{array}{l}\text { Delivery at } 32.0-33.9 \text { weeks } \\
\text { with documented fetal } \\
\text { lung maturity }\end{array}$ & 0 & 0 \\
\hline $\begin{array}{l}\text { Gestational Age at Delivery } \\
\text { (weeks) }\end{array}$ & $30 \pm 4$ & $28 \pm 3$ \\
\hline Delivery before 32 weeks & $2(50 \%)$ & $7(87.5 \%)$ \\
\hline Delivery before 34 weeks & $4(100 \%)$ & $8(100 \%)$ \\
\hline \multicolumn{3}{|l|}{ Pulmonary Maturity Testing } \\
\hline Immature & $1(25 \%)$ & $2(25 \%)$ \\
\hline Not Tested & $3(75 \%)$ & $6(75 \%)$ \\
\hline $\begin{array}{l}\text { Latency, Randomization to } \\
\text { Delivery (weeks) }\end{array}$ & $1.6 \pm 1.0$ & $1.3 \pm 1.6$ \\
\hline Less than 1 week & $1(25 \%)$ & $5(62.5 \%)$ \\
\hline 1.0 to 1.9 weeks & $1(25 \%)$ & $1(12.5 \%)$ \\
\hline 2.0 weeks or more & $2(50 \%)$ & $2(25 \%)$ \\
\hline \multicolumn{3}{|c|}{ Reason for Delivery Before 34 weeks } \\
\hline Spontaneous & 0 & $4(25 \%)$ \\
\hline Chorioamnionitis & $1(25 \%)$ & $2(25 \%)$ \\
\hline Fetal Indications & $3(75 \%)$ & $2(25 \%)$ \\
\hline
\end{tabular}

Results expressed as Mean \pm SD or N (\%).

Fetal indications for delivery included abnormal fetal heart tracings (4 cases) and fetal growth restriction with abnormal umbilical artery Doppler findings (1 case, placebo group).

their patients in the research setting and the commitments made by patients to advance clinical knowledge are not subject to the vagaries of commercial restructuring." Although vagaries in the manufacturing and approval of $17 \mathrm{P}$ were the cause of our premature trial termination, we were faced with the practical reality that these circumstances made it impossible for us to complete the trial using the formulation with which we started.

Lievre et al. [25] stated that enrollment of a patient into a research trial is "a moral contract by which the study (the investigators, the scientists, and the sponsor) agrees to use all possible means to make the patient's participation useful to the community." Certainly, had we chosen not to report the results from the 12 subjects who enrolled, their participation would not have been useful. Such a choice would not be ethically tenable. We have every confidence that those subjects who were assigned to receive $17 \mathrm{P}$ actually received pure, sterile $17 \mathrm{P}$ and that those assigned to placebo actually received a pure, sterile preparation that was 
Table 3 Neonatal Morbidity and Mortality

\begin{tabular}{lcc}
\hline & 17-Hydroxyprogesterone Caproate & Placebo \\
\hline Composite Neonatal Morbidity & $\mathbf{( N = 4 )}$ & $\mathbf{( N = 8 )}$ \\
\hline Perinatal Death & $3(75 \%)$ & $7(87.5 \%)$ \\
\hline \multicolumn{1}{l}{ Stillbirth/Miscarriage } & & 0 \\
\hline$\quad$ Neonatal Death & 0 & $1(12.5 \%)$ \\
\hline Respiratory Distress Syndrome & $1(25 \%)$ & $7(87.5 \%)$ \\
\hline Sepsis, Culture-Proven & $3(75 \%)$ & 0 \\
\hline Pneumonia & 0 & 0 \\
\hline Intraventricular hemorrhage, Grade 3 or 4 & 0 & 0 \\
\hline Periventricular Leukomalacia & $2(50 \%)$ & 0 \\
\hline Necrotizing Enterocolitis & 0 & 0 \\
\hline
\end{tabular}

Data expressed as N (\%).

Composite Neonatal Morbidity = any one or more of the listed outcomes

not visibly distinguishable from $17 \mathrm{P}$. That is, the observations here are truly valid, randomized, doubleblinded, and placebo-controlled. Though we cannot make much of the results in isolation, it is our expectation that these 12 subjects ought to be included in future metaanalyses and systematic reviews concerning the use of 17P after PROM.

We have started a virtually identical study using the FDA-approved formulation of 17P.

\section{Conclusion}

Premature termination of the study left us with a sample too small to reach conclusions about efficacy of 17P after PROM. Nonetheless, the results are valid and ought to be included in any future metaanalyses or systematic reviews of this topic.

\section{Availability of supporting data}

Please refer to the section "Description of additional data files" on the last page

Table 4 Selected other outcomes

\begin{tabular}{lcc}
\hline & 17-Hydroxyprogesterone Caproate & Placebo \\
\hline Maternal Management \& Complications & $\mathbf{( N = 4 )}$ & $\mathbf{( N = 8 )}$ \\
\hline Tocolysis in first 48 h & $3(75 \%)$ & $7(87.5 \%)$ \\
\hline Antenatal Corticosteroids & $3(75 \%)$ & $5(62.5 \%)$ \\
\hline Cesarean Delivery & $4(100 \%)$ & $8(100 \%)$ \\
\hline Preeclampsia or Gestational Hypertension & $3(75 \%)$ & $5(62.5 \%)$ \\
\hline Gestational Diabetes & 0 & $1(12.5 \%)$ \\
\hline Chorioamnionitis & 0 & $2(25 \%)$ \\
\hline Sepsis & $1(25 \%)$ & $1(12.5 \%)$ \\
\hline Neonatal Outcomes & 0 & 0 \\
\hline Birthweight, gms & $1328 \pm 547$ & $1288 \pm 525$ \\
\hline Total Hospital Stay, Days & $42 \pm 23$ & $57 \pm 48$ \\
\hline NICU Stay, Days & $42 \pm 23$ & $56 \pm 48$ \\
\hline Newborns with Congenital Anomaly** & $1(25 \%)$ & $3(37.5 \%)$ \\
\hline Adverse Events Not Tabulated Elsewhere*** & 0 & $1(12.5 \%)$ \\
\hline
\end{tabular}

Data expressed as Mean \pm SD or $\mathrm{N}(\%)$

$\mathrm{NICU}=$ Neonatal Intensive Care Unit

* One patient had received antenatal corticosteroids before PROM.

** One newborn in 17P group had ventriculoseptal defect and patent foramen ovale. Newborns with anomalies in the placebo group were 1 with bilateral inguinal hernias and hypospadias, 1 with unilateral inguinal hernia, and 1 with umbilical hernia.

*** One newborn had congenital lobar emphysema 
Table 5 The obstetrix collaborative research network

\begin{tabular}{|c|c|c|}
\hline Role & Personnel & Institutions \\
\hline \multirow[t]{4}{*}{ Investigative Sites } & Rodney K Edwards MD, MS & Obstetrix Medical Group, Phoenix Perinatal Associates \\
\hline & Melissa Ingersoll RN, CRC & Banner Good Samaritan Medical Center, Phoenix, AZ \\
\hline & Ana Braescu, RN, MS & Banner Desert Samaritan Medical Center, Phoenix, AZ \\
\hline & & Banner Sun Health Research Institute (IRB) \\
\hline \multirow[t]{3}{*}{ Investigative Site } & C Andrew Combs MD, PhD & Obstetrix Medical Group, San Jose \\
\hline & Kimberly Mallory RN & Good Samaritan Hospital, San Jose, CA \\
\hline & Stacey Maguire RN & Good Samaritan Hospital IRB \\
\hline \multirow[t]{5}{*}{ Investigative Sites } & Richard Porreco MD & Obstetrix Medical Group of Colorado \\
\hline & Kent Heyborne MD & Presbyterian Saint Luke's Hospital, Denver, CO \\
\hline & Julie Rael RN & Swedish Medical Center, Englewood, CO \\
\hline & Jeri Lech RN & Presbyterian Saint Luke's Hospital IRB \\
\hline & & HCA-HealthONE IRB \\
\hline \multirow[t]{3}{*}{ Investigative Site } & David Luthy MD & Obstetrix Medical Group of Washington \\
\hline & Tina Lopez RN & Swedish Medical Center, Seattle, WA \\
\hline & Dawn Artis RN & Swedish Medical Center IRB \\
\hline \multirow[t]{3}{*}{ Investigative Site } & George Lu MD & Obstetrix Medical Group of Kansas City \\
\hline & Janice Etzenhouser RN & Saint Luke's Hospital of Kansas City, Kansas City, MO \\
\hline & & Saint Luke's Hospital of Kansas City IRB \\
\hline \multirow[t]{3}{*}{ Investigative Site } & Wilson Huang MD & Center for Maternal Fetal Medicine \\
\hline & Judy Hancock MSN & Sunrise Hospital, Las Vegas, NV \\
\hline & & Sunrise Health IRB \\
\hline \multirow[t]{3}{*}{ Investigative Site } & Asad Sheikh MD & Spectrum Health Maternal Fetal Medicine \\
\hline & Lori Oosterman BSN, RN & Spectrum Health Hospital, Grand Rapids, MI \\
\hline & Alison Dutkiewicz RN & Spectrum Health Hospital IRB \\
\hline \multirow[t]{3}{*}{ Investigative Site } & Michael Nageotte MD & Obstetrix Medical Group, Southern California \\
\hline & Christine Preslicka BSN, RN & Long Beach Memorial Medical Center, Long Beach, CA \\
\hline & & MHS Research Administration (IRB) \\
\hline \multirow[t]{3}{*}{ Investigative Site } & Hugh Miller MD & Obstetrix Medical Group of Arizona \\
\hline & Diane Mercer RN, CCRC & Tucson Medical Center, Tucson, AZ \\
\hline & & Tucson Medical Center IRB \\
\hline \multirow[t]{3}{*}{ Investigative Site } & David Lewis MD & University of Cincinnati School of Medicine \\
\hline & Christine DeArmond RN & University Hospital, Cincinnati, $\mathrm{OH}$ \\
\hline & & University of Cincinnati IRB \\
\hline \multirow[t]{4}{*}{ Data \& Safety Monitoring Board } & Reese Clark MD & Pediatrix Medical Group CREQ, Piedmont, SC \\
\hline & Jay D lams MD & Ohio State University, Columbus, $\mathrm{OH}$ \\
\hline & Brian M Mercer MD & MetroHealth Medical Center, Cleveland, $\mathrm{OH}$ \\
\hline & Barbara Marusiak, RN, MSC & Pediatrix Medical Group, Phoenix, AZ \\
\hline Biostatistics & Anita Das, PhD & Axistat, Inc., San Francisco, CA \\
\hline \multirow[t]{5}{*}{ Trial Administration } & Kimberly Maurel RN, MS & Obstetrix Medical Group CREQ, Fountain Valley, CA \\
\hline & Kimberly Mallory RN & Obstetrix Medical Group CREQ, Campbell, CA \\
\hline & Diana Abril RN & Obstetrix Medical Group CREQ, Gilbert, AZ \\
\hline & Thomas J Garite MD & Obstetrix Medical Group CREQ, Steamboat Springs, CO \\
\hline & C Andrew Combs MD, PhD & Obstetrix Medical Group CREQ, Campbell, CA \\
\hline
\end{tabular}

CREQ = Center for Research, Education \& Quality

IRB = Institutional Review Board

Description of Additional Data Files 


\section{Additional material}

Additional file 1: Protocol, version 1.6, 17P for PROM; 17-alphahydroxyprogesterone caproate (17P) for prolongation of pregnancy in women with preterm rupture of the membranes (PROM), doubleblind randomized clinical trial; Final version of protocol, approved by IRB at each site.

Additional file 2: Data, 17P for PROM; Obstetrix Medical Group data, 17-hydroxyprogesterone caproate for preterm rupture of membranes; Results table, de-identified raw data for each participant

\section{Abbreviations}

17P: 17-hydroxyprogesterone caproate; DSMB: Data Safety and Monitoring Board; FDA: United States Food and Drug Administration; IRB: Institutional Review Board; NICU: Neonatal Intensive Care Unit; PROM: Preterm Rupture of Membranes; SD: Standard Deviation

\section{Acknowledgements}

Funding was provided by a research grant from the Center for Research, Education, and Quality (CREQ) of Pediatrix Medical Group, Inc., based in Sunrise, FL. The CREQ provided salary support for research nurses participating in the trial. Dr Combs and Dr Garite are part-time employees of the CREQ. All other physicians who participated in the study did so on a voluntary basis.

\section{Author details}

'Obstetrix Medical Group, Center for Research, Quality, and Education, San Jose, CA, USA. ${ }^{2}$ Obstetrix Medical Group, Center for Research, Quality, and Education, Steamboat Springs, CO, USA. ${ }^{3}$ Obstetrix Medical Group, Center for Research, Quality, and Education, Fountain Valley, CA, USA. ${ }^{4}$ Obstetrix Medical Group, Phoenix Perinatal Associates, Phoenix, AZ, USA. ${ }^{5}$ Obstetrix Medical Group of Kansas City, Kansas City, MO, USA. ${ }^{6}$ Obstetrix Medical Group of Colorado, Denver, CO, USA. ${ }^{7}$ AxiStat, Inc., San Francisco, CA, USA. ${ }^{8}$ Obstetrix Medical Group, 900 E Hamilton Avenue \#220, Campbell, CA, USA.

\section{Authors' contributions}

CAC drafted the protocol, manuscript, and FDA IND submission and participated in enrollment and data analysis. TJG made critical contributions to trial design, protocol, \& manuscript, and provided administrative oversight. KM coordinated FDA IND submission, participated in drafting of informed consent documents, supervised site initiation visits and training of personnel, provided oversight of data monitoring and data cleanup, coordinated DSMB meetings and documents. KM made critical contributions to protocol logistics, FDA IND submission, \& IRB documents and performed data quality monitoring. RKE, GL, and RP made critical contributions to trial design meetings, protocol finalization, and manuscript, participated in enrollment and contribution of data. AD provided biostatistical consultation during trial design and data analysis, and made critical contributions to manuscript preparation. All authors read and approved the final manuscript.

\section{Competing interests}

The Obstetrix Collaborative Research Network has received a donation of Makena ${ }^{\mathrm{TM}}$ and placebo from KV Pharmaceuticals for its new study of 17P after PROM, mentioned in the last paragraph of the discussion.

The authors declare no other competing interests.

Received: 12 October 2011 Accepted: 29 December 2011

Published: 29 December 2011

\section{References}

1. Caughey AB, Robinson JN, Norwitz ER: Contemporary diagnosis and management of preterm premature rupture of membranes. Rev Obstet Gynecol 2008, 1:11-22.

2. Mercer BM: Preterm premature rupture of the membranes. Obstet Gynecol 2003, 101:178-193
3. Amon E, Lewis SV, Sibai BM, Villar MA, Arheart KL: Ampicillin prophylaxis in preterm premature rupture of the membranes: a prospective randomized study. Am J Obstet Gynecol 1988, 159:539-543.

4. McGregor JA, French Jl, Seo K: Antimicrobial therapy in preterm premature rupture of membranes: results of a prospective, double-blind, placebo-controlled trial of erythromycin. Am J Obstet Gynecol 1991, 165:632-640.

5. Grable IA, Garcia PM, Perry D, Socol ML: Group B Streptococcus and preterm premature rupture of membranes: a randomized, double-blind clinical trial of antepartum ampicillin. Am J Obstet Gynecol 1996, 175:1036-1042.

6. Mercer BM, Miodovnik M, Thurnau GR, et al: Antibiotic therapy for reduction of infant morbidity after preterm premature rupture of the membranes: a randomized controlled trial. JAMA 1997, 278:989-995.

7. Kenyon SL, Taylor DJ, Tarnow-Mordi W, for the ORACLE Collaborative Group: Broad-spectrum antibiotics for preterm, prelabour rupture of fetal membranes: the ORACLE I randomized trial. Lancet 2001, 357:979-988.

8. Combs CA, McCune M, Clark R, Fishman A: Aggressive tocolysis does not prolong pregnancy or reduce neonatal morbidity after preterm premature rupture of the membranes. Am J Obstet Gynecol 2004, 190:1723-1728

9. Mercer BM: Is there a role for tocolytic therapy during conservative mangement of preterm premature rupture of the membranes? Clin Obstet Gynecol 2007, 50:487-496.

10. Keirse MJNC: Progesterone administration in pregnancy may prevent preterm delivery. Br J Obstet Gynaecol 1990, 97:149-154.

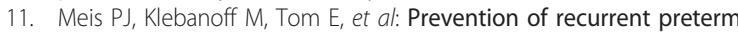
delivery by 17 alpha-hydroxyprogesterone caproate. New Engl J Med 2003, 348:2379-2385.

12. Da Fonseca EB, Bittar RE, Carvalho MH, Zugaib M: Prophylactic administration of progesterone by vaginal suppository to reduce the incidence of spontaneous preterm birth in women at increased risk: a randomized placebo-controlled double-blind study. Am J Obstet Gynecol 2003, 188:419-424

13. DeFranco EA, O'Brien JM, Adair CD, et al: Vaginal progesterone is associated with a decrease in risk for early preterm birth and improved neonatal outcome in women with a short cervix: a secondary analysis from a randomized, double-blind, placebo-controlled trial. Ultrasound Obstet Gynecol 2007, 30:697-705.

14. Fonseca EB, Celik E, Parra $M$, et al: Progesterone and the risk of preterm birth among women with a short cervix. New Engl J Med 2007, 357:462-469.

15. Hassan SS, Romero R, Vidyadhari D, et al: Vaginal progesterone reduces the rate of preterm birth in women with a sonographic short cervix: a multicenter, randomized, double-blind, placebo-controlled trial. Ultrasound Obstet Gynecol 2011, 38:18-31.

16. Facchinetti F, Paganelli S, Comitini G, Dante G, Volpe A: Cervical length changes during preterm cervical ripening: effects of 17-alphahydroxyprogesterone caproate. Am J Obstet Gynecol 2007, 196:453.e1-453. e4.

17. Borna S, Sahabi N: Progesterone for maintenance tocolytic therapy after threatened preterm labour: A randomized controlled trial. Aust NZ J Obstet Gynaecol 2008, 48:58-63.

18. Hirota Y, Cha J, Dey SK: Prematurity and the puzzle of progesterone resistance. Nature Med 2010, 16:529-531.

19. Briery $C M$, Veillon EW, Klauser CK, et al: Women with preterm premature rupture of the membranes do not benefit from weekly progesterone. Am J Obstet Gynecol 2011, 204:54.e1-54.e5.

20. CONSORT Group: CONSORT transparent reporting of trials.[http://www consort-statement.org/], accessed 27 November 2011.

21. Cruse AE: Warning letter.[http://www.fda.gov/ICECI/EnforcementActions/ WarningLetters/ucm238251.htm?sms_ss=email\&at_xt $=4 \mathrm{~d} 2386 \mathrm{ad} 3 \mathrm{e} 41 \mathrm{fbdf} \%$ 2C0], accessed 27 November 2011.

22. Combs CA, Garite T, Maurel K, Das A, Porto M, Obstetrix Collaborative Research Network: Failure of 17-Hydroxyprogesterone to reduce neonatal morbidity or prolong triplet pregnancy. Randomized, controlled trial. Am J Obstet Gynecol 2010, 203:248.e1-248.e9.

23. Combs CA, Garite T, Maurel K, Das A, Porto M, Obstetrix Collaborative Research Network: A randomized, controlled trial of 17hydroxyprogesterone caproate to prevent preterm birth in twin pregnancy. Am J Obstet Gynecol 2011, 204:221.e1-221.e8. 
24. Editorial: A curious stopping rule from Hoechst Marion Roussel. Lancet 1999, 350:155.

25. Lievre M, Menard J, Bruckert E, et al: Premature discontinuation of clinical trial for reasons not related to efficacy, safety, or feasibility. BMJ 2001, 322:603-605.

doi:10.1186/1756-0500-4-568

Cite this article as: Combs et al: 17-Hydroxyprogesterone caproate to prolong pregnancy after preterm rupture of the membranes: early termination of a double-blind, randomized clinical trial. BMC Research Notes 2011 4:568.

Submit your next manuscript to BioMed Central and take full advantage of:

- Convenient online submission

- Thorough peer review

- No space constraints or color figure charges

- Immediate publication on acceptance

- Inclusion in PubMed, CAS, Scopus and Google Scholar

- Research which is freely available for redistribution 